Loading

The Journal of the Canadian Game Studies Association

II0.1DKC.

\title{
Not Just a Slice: Animal Crossing and a Life Ongoing
}

\section{Gracie Lu Straznickas}

Volume 13, Number 22, 2020

Animal Crossing Special Issue

URI: https://id.erudit.org/iderudit/1075264ar

DOI: https://doi.org/10.7202/1075264ar

See table of contents

Publisher(s)

Canadian Game Studies Association

ISSN

1923-2691 (digital)

Explore this journal

Cite this article

Straznickas, G. (2020). Not Just a Slice: Animal Crossing and a Life Ongoing. Loading, 13(22), 72-88. https://doi.org/10.7202/1075264ar
Article abstract

This paper defines and examines a genre of videogames I call slice of life and reflects upon the use and appeal of the genre for different audiences. I develop an account of the slice of life genre by defining three critical traits: the mundane activities comprising most of the game time, the normativity of social interactions within the world, and the ongoingness of the game world in the absence of the player. Utilizing a journal and experience-based methodology, I present my own experience with chronic pain and pain management to assess how Animal Crossing: New Leaf, a game that falls into this slice of life category, was useful to me as a disabled player. My analysis not only reveals a connection between my experience in Animal Crossing: New Leaf and pain management, but also offers insight into how the slice of life genre involves different metagames for different audiences. Future work may address more case studies in further development of the slice of life genre as well as how it impacts different audiences.
Copyright Gracie Lu Straznickas, 2020

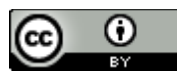

This document is protected by copyright law. Use of the services of Érudit (including reproduction) is subject to its terms and conditions, which can be viewed online.

https://apropos.erudit.org/en/users/policy-on-use/ 


\title{
Not Just a Slice: Animal Crossing and a Life Ongoing
}

\author{
Gracie Lu Straznickas \\ Human Centered Design PhD Student, DePaul University \\ gracie.straz@gmail.com
}

\begin{abstract}
This paper defines and examines a genre of videogames I call slice of life and reflects upon the use and appeal of the genre for different audiences. I develop an account of the slice of life genre by defining three critical traits: the mundane activities comprising most of the game time, the normativity of social interactions within the world, and the ongoingness of the game world in the absence of the player. Utilizing a journal and experience-based methodology, I present my own experience with chronic pain and pain management to assess how Animal Crossing: New Leaf, a game that falls into this slice of life category, was useful to me as a disabled player. My analysis not only reveals a connection between my experience in Animal Crossing: New Leaf and pain management, but also offers insight into how the slice of life genre involves different metagames for different audiences. Future work may address more case studies in further development of the slice of life genre as well as how it impacts different audiences.
\end{abstract}

\section{Author Keywords}

Animal Crossing: New Leaf; slice of life; chronic pain; disability experience; videogame genre

\section{Introduction}

Animal Crossing has always been a part of my life. In 2002, I sat with a GameCube controller held tightly in my tiny fingers as I listened to my dad read me fast-paced text rattled off by a little cat on the television screen. The snow laden Christmas morning of 2005 was filled with shrieks of joy as my sister and I played Animal Crossing: Wild World on our Nintendo DSes. In 2008 I was swinging my Wiimote and gripping at my nunchuk in Animal Crossing: City Folk before finally picking up a classic controller to use instead. In 2013 I picked up Animal Crossing: New Leaf (AC:NL) and spent the entire summer decorating my town and collecting bugs and fish. In fall, I had to put my town away for high school. Little did I know, in a few months I would be bedridden after a complication from a then undiagnosed pain condition that resulted in a two week long migraine and the inability to move easily. During my migraine and pain filled state I opened up $A C: N L$ again. Playing it fulfilled a desperate wish for the everyday experiences that the pain had quickly stripped away. Walking through my town, relief washed over me as I engaged with a familiar virtual world that had continued to exist without me. Catching up with NPCs, getting my mail, checking on my flowers and shops, all distracted me while still offering a touch of the ordinary life I was missing. 
73 Loading... The Journal of the Canadian Game Studies Association Vol 13(22): 59-71

http://loading.gamestudies.ca

This paper argues that there is a deep connection between playing $A C: N L$ and learning to manage my chronic pain. I did not consciously recognize the connection at the time, but the gameplay was nonetheless effective. Once my initial pain crises subsided, I began a quest to understand what occurred within my 570 hours of gameplay in $A C: N L$ and why I keep returning to it. I begin by briefly introducing the disability framework of biopsychosocial analysis that guides my exploration. Then, I argue that $A C: N L$ belongs to a genre I call slice of life games characterized by three qualities: mundane activities, normativity, and ongoing existence. From the hegemonic perspective, or what Stephanie Boluk and Patrick LeMieux call the "standard metagame," these are paradoxical pleasures, but I argue that they make sense as part of an alternative style of play that is connected to my experience of pain.

\section{Disability Frameworks}

To begin, I would like to briefly introduce some important concepts in disability studies that are crucial for understanding my journey with chronic pain and a connection with $A C: N L$. In a call to change our social model of disability, Crow (1996) discusses both the social and medical models. The medical model, sometimes referred to as the individual model, focuses on impairments or someone's functional limitations as the source of disadvantages in those who are disabled (Terzi, 2004). Placing blame on disabled people for their impairments through the medical model distracts from socially constructed barriers, and this misguided approach is not only harmful to those with disabilities, but promotes negative depictions of disability in media. For example, Patsavas (2014) describes how the current medical model bleeds into the media and paints chronic pain as "a fate worse than death" (Patsavas, 2014, p. 203). As Kafer (2013) suggests, the idea that disability needs to be cured is "colored by histories of ableism and disability oppression" (Kafer, 2013, p. 20).

The social model, as Crow explains, centers around socially constructed barriers as the source of disability, putting special focus on how to counter this social oppression. The social model of disability has several limitations of its own, hence Crow's (1996) call to change it. Crow's main critique is that the heavy focus on the creation of "disability" through social barriers often takes away from the actual experience of impairment. In other words, the social model excludes the importance in discussing the experience of having an impairment. In creating the social model, disability scholar Michael Oliver sought to fight back against stereotypical medical model based viewpoints of the disabled (Terzi, 2004). While this particular framework generated important discussions among disability scholars, the simplicity of the social model erases several different experiences and intersectionalities, and fails to grasp the many layers of disability (Samaha, 2007).

To summarize, every experience in disability is unique. The medical and social models have limitations that fail to include all people and aspects of a disabled experience. Furthermore, an attempt to create a universal definition with only the standards of my own chronic pain would exclude many of those who define themselves as disabled people. In an effort to avoid an exclusive framework of disability, I will be approaching $A C: N L$ through a popular method in pain management called the biopsychosocial model (Keefe \& France, 1999; Revivo et al., 2019). The biopsychosocial framework takes into account biology, psychology, and social aspects of 
74 Loading... The Journal of the Canadian Game Studies Association Vol 13(22): 59-71

http://loading.gamestudies.ca

pain to better develop proper management unique to each individual. Before saying any more on this approach, it is important to understand the process of my experiences with pain management as an individual.

One practice that responds to the complications of impairment, without framing disability as a condition to overcome, is pain management and rehabilitation. In 2014, I attended a pediatric pain rehabilitation program that helps adolescents function with chronic pain and return to school and life activities. Pain management is an important aspect of the program and is a process people with chronic pain have to develop in order to adjust daily internal facets of pain, their expectations and mindset, as well as external facets of physical ability and social barriers.

This pain rehabilitation program develops skills to help each patient coexist with a society that expects all bodies to operate under the same "typical" state of physical ability. Pain management is not a cure and is not meant to be one. The program I attended utilized the biopsychosocial method to address pain management. For example, pain journals required me to record my activities, feelings, and pain levels to discover connections between my pain and physical experiences, emotions, and events in my life. This helped me to develop meaning-making reflections. I then discussed these entries with a psychotherapist and other members of the pain rehabilitation program. It was during my three months in the pain management program that I returned to $A C: N L$. In order to illustrate the connections between my experience with $A C: N L$ and pain management, I will be quoting from my own journal entries throughout the following discussion. This self-reflective analysis method offers an ethnographic look employed in several disability studies as well as human centered design practices (Dysvik and Furnes, 2018; Gaver, 1999; Patsavas, 2014; Williams, 2018). Additionally, I will be referencing the biopsychosocial framework in pain management as opposed to a structured framework on disabilities and impairments.

In the following sections I describe qualities of $A C: N L$ and argue that there is a connection between the form and genre of the game and my lived experience of chronic pain that finds expression in a particular style of play. It is important to remember that other experiences of disability and pain may not coincide with mine. However, as Dysvik and Furnes (2018) note in their study of chronic pain, while each experience is unique, personal stories have the potential to reveal a deeper truth about pain. In this respect, my own experience with chronic pain and its connection to $A C: N L$ serves as an addition towards a deeper truth in both the experience and management of chronic pain.

\section{Slice of Life Games}

Animal Crossing is what I will call a slice of life game. This genre can be used as an umbrella term that covers several other well-known titles such as Harvest Moon: Another Wonderful Life (Natsume, 2005), and Chibi-Robo! (Nintendo, 2006), to lesser known titles like Bernband (van den Boogaart, 2014), and One Night Stand (Kinmoku, 2016). Given its range, slice of life games have several sub-genres utilized to further define the game mechanics offered. This includes social simulation games like The Sims (Electronic Arts, 2000-2019) or Tomodachi Life (Nintendo, 2014), or farming games like Stardew Valley (Chucklefish, 2016). My interest in utilizing Animal Crossing: New Leaf as my case study for the slice of life genre is due to its 
75 Loading... The Journal of the Canadian Game Studies Association Vol 13(22): 59-71

http://loading.gamestudies.ca

mismatch with the other generic categories used to group these games; Animal Crossing is neither a robust social simulation nor organized by the rhythms of crop harvests common to farming games. To develop a description of this genre however, it becomes important to determine the characteristics that do group these games together.

The term slice of life genre captures some of the alternate affordances of $A C: N L$ that get overlooked in these games and highlights its connection to other liminal and feminized genres like the ambient narratives of walking simulators or the slow friendships of virtual pet games. The term slice of life has a varied history as a genre marker in different media and denotes "a realistic and detailed portrayal... of incidents typical of everyday life" ("slice of life," 1938). Originally translated from the French term "tranche de vie" it was used by playwright, Jean Jullien (Styan, 1983, p. 35). Jullien wrote that "a play should be a living segment of life," and slice of life meant "The scene was to be as if set in a room with its fourth wall removed" (Dickinson, 1927, p. 123; Styan, 1983, p. 35). The slice of life gained popularity within the French naturalism movement greatly influenced by Emile Zola's work which rejects romanticism in favor of more realistic depictions of life. Although naturalism was deemed pessimistic at the time, the slice of life genre represents both the good and bad experiences of life.

More recently, slice of life has become a term in writing about Japanese manga and anime. Tanaka (2014) discusses nichijōkei, or 'slice of daily life' fiction, and notes several common characteristics: a story set in real locations in contemporary Japan; simple plots and superficial conversations; and characters who are predominantly girls. Tanaka argues that these features help create a sense of realism. Realism is a fraught term within video games. Galloway (2006) expands on the concept of game "reality" by contrasting realism and realisticness. Realisticness, he notes, is a technical ideology that demands higher polygon counts and more detailed textures, whereas realism reflects "critically on the minutiae of everyday life, replete as it is with struggle, personal drama, and injustice" (Galloway, 2006, p. 75). Utilizing history and current definitions of slice of life, I argue that there are several common aesthetic qualities present in most slice of life games.

Slice of life games offer a contained world that is a minor and deflated version of our own. Though they may showcase struggles among characters, they are not inherently structured by conflict and most conversation dwells on superficial topics. Though the game world and player may change, there is generally no overarching storyline causing dramatic shifts. While the player has an active role in the world, the mechanics focus on mundane and everyday activities. At first glance and from the dominant way of playing video games, these qualities seem antithetical to the pleasures of video games. They eschew meaningful choice, limit player agency, lack a rich story, undermine power fantasies, and decenter the player's character. While slice of life games often have elements that fit traditional game structures, as in Ian Bogost's reading of accumulating items and paying off debt, they also make fundamentally different modes of play possible. Mundane activities, normativity, and ongoingness each offer minor fantasies and pleasures that resonate with my experience of chronic pain and, I think, beyond. In order to further develop these ideas and the structure of the genre, I return to my time with Animal Crossing: New Leaf and analyze the game's formal elements in tandem with my recollections and notes regarding my process of becoming better at managing my pain. 
76 Loading... The Journal of the Canadian Game Studies Association

Vol 13(22): 59-71

http://loading.gamestudies.ca

\section{Mundane Activities: a leisurely pace}

The slice of life genre includes the minutiae of everyday life. Mundane activities are the boring tasks we prefer to ignore in our real world lives, things that are time consuming, regular, repeated, and unexciting; they can also be tasks that become mundane when reframed as such in the game world. In $A C: N L$ some of these activities include: fishing, catching bugs, digging holes, hitting rocks, gathering fruit, chopping trees, planting flowers, walking, and organizing your pockets. While fishing, for example, the player must stand patiently along the side of a river or at the shore of the vast sea while keeping their attention silently focused in order to react quickly when a fish bites. The player may also need to keep an eye on the time, season, weather, and fish silhouette if they are searching for a specific species. An even less dramatic example is how the player organizes their pockets. The game only gives the player 16 inventory slots and players must regularly rearrange their items, going back and forth in a process reminiscent of a tedious Tetris. Most mundane activities are designed to slow the player down, something video games often try to avoid. An important question for slice of life games, then, is to ask what value this slowness takes on.

While many games have movement as a starting point that leads towards other forms of engagement, movement in $A C: N L$ asks the player to play in a leisurely way. Slowness takes on value because it benefits the player through visual and mechanical rewards. Mechanically speaking, walking, a mundane activity on its own, leads players towards an array of options and new tasks. Whether it be a mark in the ground to indicate where to dig, a strange rock that wasn't there the day before, or the sound of a bug buzzing in the distance, players need to keep an eye on the state of their town in order to note day to day differences. The confined space of the village allows players to do an entire lap of their town, and the animals' homes further encourage random exploration.

In order to encourage slowness, running, instead of walking, through town has the direct negative consequence of eventually turning the grass to dirt. This outcome is frustrating to reverse, and leads some players to avoid running entirely (Medz, 2016). For others, the choice to walk has more to do with protecting carefully curated flowers as opposed to erosion. In either case, the choice to walk slows down the game. For players undeterred by the effects that running has on the plant life, it also results in the player's character occasionally tripping. This pauses their movement by forcing them to sit through an animation of the character standing back up and making a bashful expression. Conversely, the game rewards slow movement with a rhythmic animation of slow swinging arms and the sound of the avatar's feet padding through lush grass.

Why then do players enjoy a game that pressures them to move slowly when there are so many others that allow them to run and dash? Pruett (2019) offers one answer in explaining a similar outcome of Stardew Valley's (Chucklefish, 2016) success with millennials. The game uses mechanics and narrative to reflect values that are unattainable in the present despite cultural expectations that still venerate these values. For millennials, Stardew Valley allows an experience they cannot otherwise have. Slowly walking does not have the same class and generational connotations, but it activates a similar structure of fantasy for ordinariness. $A C: N L$ 
77 Loading... The Journal of the Canadian Game Studies Association

Vol 13(22): 59-71

http://loading.gamestudies.ca

similarly offered me a world where I could move without consequence of pain. This specific style of play in regard to my disability gave me the fantasy of free movement.

\section{Pain Journaling}

To offer insight into the concept of free movement, I introduce the term catastrophizing. Catastrophic thinking or catastrophizing in relation to chronic pain refers to the anxiety filled mental state caused by consistent body pain. The Pain Catastrophizing Scale (PCS), developed by Sullivan et al. (1995), describes catastrophic thinking through three levels. Best represented in the PCS user manual, these three levels are as follows: rumination "(I can't stop thinking about how much it hurts)," magnification "(I worry that something serious may happen)", and helplessness "(It's awful and I feel that it overwhelms me)" (Sullivan, 2009, p. 4). Thinking catastrophically becomes the reality of movement for many with physical disabilities. To illustrate the connection between this concept and my experience, I reference a few entries from my pain journal below:

"4/1/14: I'm scared to go dress shopping tomorrow it will hurt

4/2/14: Dress shopping will be hard

4/3/14: Dress shopping was hard."

Here I have documented a three-day fear process into something as simple as shopping for and trying on clothes. Some of my thoughts at the time were warranted, but the catastrophic perspective further fueled my internal anxiety about my abilities. This is where a connection to the fantasy of free movement offered in $A C: N L$ becomes increasingly important. More explicitly, another entry from my pain journal reads:

\section{"3/30/14: moving my body sucks"}

This annoyance at basic movement is a theme throughout my journals, and though four words cannot express my experience in learning to manage chronic pain, this entry reveals movement not only as a physical burden but as a mental one as well. Hyperfocusing on every movement often made the concept of general activity less appealing. Exploring space in a virtual world, and particularly walking, did not result in the same suffering. What made $A C: N L$ especially intriguing to me while I was bedridden was that my part in the game was not that of an athletic hero in a role I could never hope to achieve. Instead, I was on the same level as everyone else in the town and it was a level I began to feel was attainable in my own life. At the time of my pain journal, my goals were simple; I wanted to get a dress and to attend graduation. $A C: N L$ simplified this activity, and allowed me to see my player character try on clothes quickly and easily. It was a fantasy of minor power I could not have otherwise accessed. It gave me the chance to experience the agency behind the act. More generally, the fantasy that $A C: N L$ allowed me to indulge in was not one of saving the planet or winning a war, but of walking around and enjoying the basic activities of life. This fantasy invoked a more positive picture of my future by giving me the context to explore it. While the minutiae of daily life may be tiring when it is present, it is easy to start missing it when it is suddenly no longer possible. This alone made me a likely player to engage in all the mundane activities for myself, the beautification of my town and the good feelings of my neighbors being a happy byproduct. 
78 Loading... The Journal of the Canadian Game Studies Association

Vol 13(22): 59-71

http://loading.gamestudies.ca

In reviewing the many mundane activities present to the player in $A C: N L$, I focused on the purposeful slowness expected in player movement. This leisurely pace highlights the experience of mundane tasks instead of erasing them or distracting the player's attention elsewhere. The focus on daily life, including common tasks, is crucial for the slice of life genre. With a lack of appreciation for the mundane, walking in most games generally focuses on getting the player to another task instead of being an activity in and of itself. Walking simulators such as Bernband demonstrate the concept of exploration without destination, much like in $A C: N L$. The ability to not only complete a mundane activity, but to be encouraged to do so and to enjoy it, was important in my pain management process and reflection. Slowness and the mundane offered me virtual interactions with daily life that I no longer had in my day-to-day.

\section{Normativity: obligation in expectations}

The slice of life genre in anime is often thought to give the feeling of "hanging out with your friends" according to several viewers (blautoothdmand, 2017; brightbier, 2014). Games have the unique ability to not only show this experience, but to allow the player to participate more actively within it. While the mundane aspects of the slice of life genre focus on player actions, this section of normativity will delve into the question of why a player may seek out games like $A C: N L$ that present these societal and social norms.

Before I continue, I want to be clear that my exploration is about why normativity, both positive and negative, was useful in my pain filled state, regardless of what the content of those norms were. As I discussed in connection with chronic pain and disabilities, societal norms and expectations can cause direct and indirect harm. Anthropy (2013) specifically notes the dangers of normativity regarding identity in $A C: N L$. She references the player character's only choice of pale, white skin and the enforced gender roles through confused comments from animals when the player dresses up in non-gender normative clothing. Anthropy explains that positive representation within the game comes more from the players deriving their own meaning than from purposeful inclusion by designers. The paradoxical enjoyment I felt from the normative pressures in $A C: N L$, however, is part of what makes this genre interesting for my analysis.

Normativity in the Animal Crossing series comes in many flavors: receiving letters, talking to NPCs, bargaining with neighbors, getting a haircut, returning lost items, hanging out with animal friends, and even going to concerts. Many social interactions, for example, begin with greetings and other pleasantries such as nicknames and catchphrases. Letters always include a greeting and farewell, something the player can edit but cannot remove. While some of these activities have a mundane quality to them, it is the inclusion of NPC interaction that sets them apart. It is also how these interactions occur that fully develops the concept of normativity in $A C: N L$ and this is best shown through the player's cooperation in presented social values, obligation, and vulnerability.

When asked about what values a game like $A C: N L$ upholds, producer Katsuya Eguchi comments that "everyone has different values ... Your town becomes a reflection [of that]" (Nutt, 2013). While this may be true concerning the more tangible values within the game, there are inherent social values imbedded within NPC interactions. $A C: N L$ is not shy in forcing the player to abide by certain social rules. While there are opportunities to be rude in conversation the choices in 
79 Loading... The Journal of the Canadian Game Studies Association Vol 13(22): 59-71

http://loading.gamestudies.ca

most scenarios force a level of cordial behavior. Brown and Marklund (2015) note that the process of selling an item in $A C: N L$ takes more inputs than the average game, and that these inputs are focused around dialogue. They utilize this to reflect that interactions between players and NPCs are important in $A C: N L$ (Brown \& Marklund, 2015). Most of these extra dialogue screens imply an expected behavior that I will explore through examples of shop NPC interaction.

Every NPC that sells items in $A C: N L$ has a standard greeting and farewell dialogue for interactions with the player. These range from "Welcome! Welcome!" to "Hello! Welcome to the handmade-fashion palace of the one and only Able Sisters!" Some NPCs focus on introducing their business while others simply say hello. Gracie, the haughty, high-fashion giraffe, however, lacks these pleasantries. Gracie is known within the series for being rude, impossible to get along with, and for putting down others based on poverty and appearance. In $A C: N L$ she is less cruel, but still retains some of her past behaviors. Having her, someone even the villagers consider to be conceited, as the only product selling NPC without a greeting works to further the player's expectation of particular social values in $A C: N L$. Through Gracie, the game critiques arrogance, narcissism, and superiority. This is further encouraged by the mundane activities implying cooperation among townspeople and further generating the point of cordial behavior among player and NPCs.

When visiting Harriet at Shampoodle, conversation is built into the actual process of choosing a hairstyle. Unless the player is aware of the specific inputs, Harriet ultimately is the one who decides the final look by offering strange choices such as, "Are you wanting to fit in at work and the business world? Or do you prefer more private occasions?" to decide the hairstyle. This works to create a bond between player and stylist through a loss of agency and forced dependency. When talking to Harriet afterwards, she has a range of comments, one of them being "I really think that hairstyle suits you perfectly, sugar!" If the player sits back in the haircut chair Harriet will sadly refuse the second offer of 3,000 Bells, the game's currency, and explain that she only accepts one request per day. She notes that, "if you change too much all at once, nobody will be able to tell it's you anymore." In this example, the player has no option to ask Harriet for a redo and is instead tasked to wait the day out in humiliation if they dislike the cut. While an NPC's opinion does not generally note the feel of the game, since Harriet is the only way the player can change their hairstyle, her opinions are more than just flavor text. By blocking the player's ability to have multiple haircuts in one day, Harriet demonstrates values that $A C: N L$ upholds such as self-love, trust, and the returning notion of cooperation.

Unlike other Animal Crossing titles, $A C: N L$ appoints the player to the status of mayor. While the responsibilities of a mayor may be more than that of a villager, there is little to differentiate the player's role from the rest of the neighborhood. In reference to Animal Crossing: City Folk, Murphy and Zagal (2011) explain that many of the interactions with neighbors indicate worldbuilding elements that don't involve the player. For instance, there are relationships between the NPCs that are referenced indirectly in conversation. They note that the Animal Crossing world doesn't consider the player as a main character, but rather as another participant in the neighborhood as a whole (Murphy \& Zagal, 2011, p. 76). $A C: N L$ continues this trend despite, but also through, the player's mayoral role. Animals will ask the player character for specific additions to the town, making their input crucial in unlocking more public works projects. In their suggestions, the animals hint at social obligations of a mayor that the player is 
80 Loading... The Journal of the Canadian Game Studies Association

Vol 13(22): 59-71

http://loading.gamestudies.ca

meant to uphold. Whether the player chooses to engage in these public works projects or not does not change the gameplay. However, the NPCs come to expect it regardless. While mayoral duties can be ignored, the player cannot avoid the inescapable expectations to give and to do in order to build their relationships.

Neighbors asking the player to give them items or complete specific tasks for them is a classic mechanic in Animal Crossing. Much of the game's activities are centered around doing things for neighbors and spending time conversing with them. A common request from villagers is to ask the player for a specific kind of bug or fish. Depending on the personality of the villager, the bug or fish they ask for could be easy or difficult to find. Sometimes villagers will ask the player for furniture that fits their specific needs and other times they will attempt to buy an item right out of the player's pocket, often boldly offering too low of a buying price. While in theory refusal of coded behavior should warrant easy response, the normativity generated among the friendships built with neighbors makes this more difficult.

When neighbors ask for something, they are generally explicit in what they want and why they are asking the player. The player themself cannot ask for specific items from villagers, so NPCs must return the favor for completed tasks in gifts of random Bells, shirts, and furniture instead. They gift items without knowing if the player wants them, sometimes telling the player to "toss" the item if they don't like it. In presenting these gifts without assured positive response, the NPCs demonstrate vulnerability which makes it difficult to turn them down. As Brown (2012) reflects in her TEDx talk, "to invest in a relationship that may or may not work out" is a crucial example of vulnerability. The villagers in $A C: N L$ approach the player with the goal of friendship, putting effort into it regardless of what the player feels. In commenting on how villager characters approach the player, Katsuya Eguchi explains that "they all still default to loving the player character" despite different personality traits (Nutt, 2013). This default approach in connection to their vulnerability helps to explain why neighbors' requests are so hard to turn down. Even if the player does not abide by the normativity portrayed in the world of $A C: N L$, the game's mechanics inhibit knowledge on how refusal and acceptance of tasks actually induces friendship number values. This lack of mechanical knowledge on how reactions truly impact relationships paired with the presented vulnerability in the NPCs can engage a level of guilt in the player for going against the game's normativity. Cooperation, in this regard, is the antidote to guilt by once again engaging the player in $A C: N L$ 's expected normativity.

\section{Pain Journaling}

Regardless of if the social expectations are good or bad, outside opinions are important for crafting performances of oneself and even generating a personal identity (McEwan, 2015). While the social norms that $A C: N L$ forces on the player are small in comparison, feedback from my virtual town was important to me. While I didn't always agree with what my animal neighbors had to say, feeling my internal disagreement was important in understanding myself. This interaction with NPCs offered an opportunity for me to develop ideas surrounding my real life situation and my real friends' expectations. As I noted in my pain journal:

“3/26/14: I don't want people to be mad at me if I can't do something very well

3/27/14: I miss my friends I wonder if they miss me?

3/28/14: i think people are lying when they say i'm pretty

4/2/14: Is everyone disappointed in me?" 
When finally reunited with my real life friends, they appeared strained in an attempt to respond to my situation "correctly." They began treating me as stronger or more fragile than before by placing me either on a pedestal of strength or in a sugar-coated bundle of concern. While the support and concern were appreciated, the execution was misguided and hard to correct given the medical model of pain infiltrating cultural understanding of disability. Furthermore, with them having good intentions, it felt wrong to react negatively towards my friends' attempts at understanding my illness. While I would calmly adjust a friend's position now, at the time I lacked a proper approach to well-intentioned ignorance. This is where the alternative social world of $A C: N L$ not having that same stigma of my disability was so powerful. My virtual neighbors still held their own opinions but had no frame of reference to react upon my real life condition. Some NPCs held me in higher regard than others, but none of these expectations were based upon my abilities. For example, the "Cranky" villager personality type I favored continued to be blunt and brutal in opinions as opposed to my real life friends who were suddenly sugarcoating their words.

As I began to question several aspects of myself and how others in my real life viewed me, $A C: N L$ further allowed me insight into how I viewed myself and my worth. The vulnerability shown by the neighbor NPCs in asking me to complete tasks for them by extension caused me guilt when I was unable to match or respond appropriately. I found I held an inherent belief that if I was not of actionable value to those that I loved, I was not worth their time. This is where my fear of my high school friends forgetting me came from: the fear that if I was not doing things for them that I would be forgotten.

Interactions in $A C: N L$ embodied daily interactions I could no longer partake in, as well as the social guilt I needed to feel in order to internally develop my self-worth beyond it. The obligations as presented in $A C: N L$ are limited in comparison with real life but still offer unspoken expectations that feed into the guilt of not completing them. This is where it was important for me to experience normativity that didn't necessarily benefit me but was reminiscent of the world I was missing and one that I would need to re-enter soon. In this way, $A C: N L$ helped keep me prepared for the mental exercise of normativity that I would soon have to engage with on a permanent level again.

The inclusion of these social norms gives power to the slice of life genre. What $A C: N L$ lacks in well-developed personalities it makes up for in consistency and expectations in social obligation. The eight basic neighbor personality types offer a promise of a daily in-game "return to normal" while still offering a sliver of realism that requires the player to encounter the normativity they are forced to endure in real life. Practicing cordial behavior while managing more complex issues like obligation and guilt prepared me for re-entry into the real world. Vulnerability, a positive quality, is present in the neighbors more than in real life relationships and creates conflict within the player over how they choose to respond. All of these elements factor into normativity and expected performances in society, and reached a particular part of my life that was missing during my pain filled state.

\section{Ongoingness: unpausable reality}


Ongoingness in slice of life videogames refers to the never-ending nature of play and the game world's continued existence. In the slice of life anime genre, this is sometimes shown through the "return to normal" end of an episode or skit. The passage of time is both important and ignored, capturing characters in a timeless setting. In response to a question regarding the long playtime of $A C: N L$ producer Katsuya Eguchi explains that, "at a certain point it will end, but in the same way that life does, every day -- to day, to day, to day -- it keeps going" (Nutt, 2013). In $A C: N L$, ongoingness is best reflected through the inclusion of a real-world clock, dynamic weeds and flowers, NPCs' lives, changing seasons, holiday events, flower breeding, and even the character Isabelle and how she "fills in" for the player when they're gone. For my purposes I will be focusing mostly around the addition of the real-world clock, and the NPCs' lives to ask what value a continuous world has to a particular player and playstyle.

Katsuya Eguchi reflects that the intent behind the real world connections in $A C: N L$ helps create a parallel world, "a world that's kind of similar to your own but also different" (Nutt, 2013). The inclusion of months, seasons, and real-world time not only keeps the player tethered to their own real life experience but asks them to manage two unpausable worlds. Being occupied with realworld holidays, for example, can cause the player to miss virtual ones. Leaves, bushes, and grass change with the seasons as the weather switches from a rainy fall afternoon to a snowy winter's night. Seasonal changes in $A C$ : NL bring not only visual change, but mechanical change as different species of bugs and fish are available based on the time of year and day. Weekly events like a visit from K.K. Slider at 8:00 p.m. every Saturday night are utilized as a mechanic for the player obtaining music for their home, requiring them to note the time and participate if they hope to receive new songs. The real-time clock affects the player daily, determining when neighbors wake up and when stores open their doors. $A C: N L$ expects a level of balance from players in their enjoyment of both their real and virtual worlds.

In its unstoppable time, $A C: N L$ resists being one contained gameplay experience that occurs over the span of a week and instead allows the player the opportunity to engage daily, to find balance. Given the many holidays, seasons, and special events, the full $A C: N L$ experience cannot technically be had until at least one full real-time year has passed. In this way, enjoyment of the game cannot always be pinpointed towards one single event. Instead, $A C: N L$ provides experience and meaning through its ongoingness, through the hours required to catch a rare bug, the days spent preparing for a holiday, or the months spent saving Bells to pay off a loan. The real-time clock offers more fulfillment in reaching long term goals, but also brings with it unstoppable change. Animals will move, flowers will die, and furniture will go undusted as the town changes when the player is not engaging with it. Change is unavoidable in $A C: N L$. Even if the player engages daily, the inclusion of independent NPCs engages realism in routine.

In adjusting to an unpausable reality, NPCs utilize routine. As pointed out by Brown and Marklund (2015), the Animal Crossing series does what it can to make NPCs break from the bounds of code and player control (Brown \& Marklund, 2015, p. 14). Murphy and Zagal (2011) confirm this, noting the reinforcement that NPCs appear to control their own lives as they mosey about the town following their own schedules (Murphy \& Zagal, 2011, p. 76). AC:NL has eight neighbor personality types that allow for diversity in conversations and routines. "Snooty" villagers, for example, go to bed at around 2:00 a.m. whereas "jock" villagers go to bed at 12:00 
83 Loading... The Journal of the Canadian Game Studies Association Vol 13(22): 59-71

http://loading.gamestudies.ca

a.m. The villagers will have different comments depending on the time and their routine. Even after the player has read every possible interaction, the animals continue to feel alive as they redecorate their homes, change their outfits, and stroll around the town independently.

NPC agency continues to be represented in how the villagers move in and out of town. The player often cannot stop an animal from moving. The process of who lives in the player's town, in regard to the initial launch of $A C: N L$, is random. Stopping an animal from moving out is only possible by way of directly intervening, catching the neighbor before they pack up to leave and begging them to stay. In order to achieve this direct intervention, the player has to consistently play in the hopes that they may catch rumor of the villager's plan to move out. NPCs individually adjust to unstoppable time which in turn gives the player little option but to do the same. The game presents not only the necessity of balance, but how one must adjust to it through routine.

\section{Pain Journaling}

In dealing with my own physical pain, I was unable to help others with their problems. It weighed on me when my friends couldn't rely on me the same way they were used to, yet when they continued to uphold that expectation I began to feel bitter and misunderstood. In one of my pain journals I wrote:

“4/2/14: I don't want to deal with other people's problems anymore"

$A C: N L$ 's unique form of ongoingness provided me with a friend that enjoyed my presence but didn't need me. My town cheered when their mayor returned but didn't close up shop when I left. The game continued on regardless of if I was playing or not. My animal friends would sometimes scold me for staying away for so long, always noting the exact number of months I was gone as if they'd been counting the days, their anger fading fast as it was replaced with joy. It offered me the unique playing ground to prioritize my own needs over the needs of my virtual world. In my practice of balance, I connected the routine required for pain management with the routines of my animal neighbors. Even with the inclusion of social obligations and normativity, neighbors are relatively quick in returning to the mundane tasks of their daily lives even after a miniature reunion with the player. In $A C: N L$ I felt important to the community but not crucial for its continued existence. Even now, all my Animal Crossing towns continue on without me.

NPC values bring normativity to mundane activities while ongoingness connects realism to NPC and world interactions. In its connection to real-world time, $A C: N L$ removes player agency in a way reminiscent of our everyday lives. The NPCs further uphold realism in $A C: N L$ with how they use routine to adjust to their unpausable reality. In presenting the NPCs with their own lives and schedules $A C: N L$ better represents a life ongoing. In understanding pain management, I struggled to find balance between life and my own needs, so the opportunity to practice within a virtual world was useful. For my town in $A C: N L$ to continue without me became a comfort that allowed me the opportunity to asses myself and my own existence from another frame of mind.

\section{Conclusion}


84 Loading... The Journal of the Canadian Game Studies Association Vol 13(22): 59-71

http://loading.gamestudies.ca

The slice of life genre in videogames offers a blend of mundane activities, normativity, and ongoingness. $A C: N L$ demonstrates the genre through respect for a leisurely pace, social norms in NPC interactions, and an unbreakable connection to our real world, whether through code, text, or otherwise. When dealing with chronic pain management, these elements were crucial in both keeping me distracted and engaged: distracted in the sense that I was able to remove myself from my current situation into a fantasy, and engaged in the sense that I was also unable to fully immerse myself in the game considering all of its real-world connections. This balance between myself and $A C: N L$, between player and game, brings to mind a quote from Keogh (2018) that states that "Videogame play is a complex interplay of actual and virtual worlds as perceived through a dually embodied player" (Keogh, 2018, p. 55). In the case of $A C: N L$ and the slice of life genre, this concept holds an important truth within it. There are further connections towards pain management and the idea of body and mind connection. As Bullington (2009) references in way of health, "I am my body, but when my body doesn't work, I experience a split between myself and my body, and my body is no longer me." In $A C: N L$ the bond between our real world and digital town feeds off of the harmony achieved through balance. My play in $A C: N L$ allowed a deeper balance between my internal self and my external body. The slice of life genre offers more realistic fantasies presented in a digestible way that videogames allow experience within. The opportunity for someone in my situation to experience something I physically could not, while being inserted into a familiar enough world gave me the opportunity to re-imagine my goals as more achievable and to never be shamed at their simplicity. $A C: N L$ may only be a slice of life, but it just so happened to be the exact slice that I was missing.

\section{References}

Anthropy, A. (2013). Crossing a Line: Gender Identity in Animal Crossing. Retrieved from Tiny Cartridge website: https://tinycartridge.com/post/52624986197/crossing-a-linegender-identity-in-animal

blautoothdmand. (2017, December 27). The Appeal of Slice of Life [The Artifice]. Retrieved from The Artifice website: https://the-artifice.com/slice-of-life-anime/

Bogost, I. (2008). The Rhetoric of Video Games. In K. Salen (Ed.), The Ecology of Games: Connecting Youth, Games, and Learning (pp. 117-140). The MIT Press.

Bogost, I. (2013, September 5). Consumption and Naturalism in Animal Crossing. Retrieved from http://bogost.com/writing/consumption_and_naturalism_in_/

Boluk, S., \& LeMieux, P. (2017). Metagaming: playing, competing, spectating, cheating, trading, making, and breaking videogames. Minneapolis: University of Minnesota Press.

Bullington, J. (2009). Embodiment and Chronic Pain: Implications for Rehabilitation Practice. Health Care Analysis, 17, 100-109. 
85 Loading... The Journal of the Canadian Game Studies Association Vol 13(22): 59-71

http://loading.gamestudies.ca

brightbier. (2014, November 4). The Slice-of-Life Genre - Why is this a Thing?

[Multimedia]. Retrieved from The Vault: The McMaster Multimedia Website:

https://thevaultpublication.com/2014/11/04/the-slice-of-life-genre-why-is-this-a-thing/

Brown, A., \& Marklund, B. B. (2015). Animal Crossing: New Leaf and the Diversity of Horror in Video Games. DiGRA 2015 Conference: Diversity of Play: Games - Cultures - Identities, 16.

Brown, B. (2010). The Power of Vulnerability [Video file]. Retrieved from https://www.ted.com/talks/brene brown_on_vulnerability?language=en

Brown, B. (2012). Listening to Shame. [Video file]. Retrieved from https://www.ted.com/talks/brene_brown_listening_to_shame/transcript?language=en\#t$\underline{890393}$

Chucklefish. (2016). Stardew Valley [Computer Software]. ConcernedApe. London, England.

Crow, L. (1996). Including All of Our Lives: Renewing the social model of disability. In J. Morris (Ed.), Encounters with Strangers: Feminism and Disability. London: Women's Press.

Dickinson, T. H. (1927). An Outline of Contemporary Drama,. Biblo \& Tannen.

Dysvik, E., \& Furnes, B. (2018). Living a meaningful life with chronic pain-Further follow-up. Clinical Case Reports, 6(5), 896-900. https://doi.org/10.1002/ccr3.1487

Electronic Arts. (2000-2019). The Sims series. Maxis. Redwood City, California, U.S.

Galloway, A. R. (2006). Gaming : Essays on algorithmic culture. Retrieved from https://ebookcentral.proquest.com

Gaunt, K. D. (2006). The Games Black Girls Play: Learning the Ropes from Double-Dutch to Hip-Hop. New York and London: New York University Press.

Gaver, B., Dunne, T., \& Pacenti, E. (1999). Design: Cultural probes. Interactions, 6(1), $21-$ 29. https://doi.org/10.1145/291224.291235

Golumbia, D. (2009). Games Without Play. New Literary History, 40(1), 179-204. https://doi.org/10.1353/nlh.0.0077

Holley, W. B. (2017). Am I my brother's keeper? Émile Zola's Thérèse Raquin as a retelling of Cain and Abel. Relief - Revue Électronique De Littérature Française, 11(2), 57. https://doi.org/10.18352/relief.975

Kafer, A. (2013). Feminist, queer, crip. Bloomington, Indiana: Indiana University Press. 
86 Loading... The Journal of the Canadian Game Studies Association Vol 13(22): 59-71

http://loading.gamestudies.ca

Keefe, F. J., \& France, C. R. (1999). Pain: Biopsychosocial Mechanisms and Management. Current Directions in Psychological Science, 8(5), 137-141. https://doi.org/10.1111/1467-8721.00032

Keogh, B. (2018). A play of bodies: How we perceive videogames. Cambridge, Massachusetts: The MIT Press.

Kinmoku. (2016). One Night Stand [Computer Software].

Knutson, E. M. (2001) The Natural and the Supernatural in Zola's Thérèse Raquin. Symposium: A Quarterly Journal in Modern Literatures, 55:3, 140-154, DOI: $10.1080 / 00397700109598538$

McEwan, B. (2015). Identities in Networked Locations. In Navigating New Media Networks: Understanding and Managing Communication Challenges in a Networked Society (pp. 33-45). Lexington Books.

Medz. (January 1st, 2016). Re: Do you run in your town? [Online discussion group]. Retrieved from https://gamefaqs.gamespot.com/boards/997811-animal-crossing-newleaf/73173462

Murphy, J., \& Zagal, J. (2011). Videogames and the Ethics of Care: International Journal of Gaming and Computer-Mediated Simulations, 3(3), 69-81. https://doi.org/10.4018/jgcms.2011070105

Natsume. (2005). Harvest Moon: Another Wonderful Life [GameCube]. Marvelous Interactive. Tokyo, Japan.

Nintendo. (2002). Animal Crossing [GameCube]. Nintendo EAD. Kyoto, Japan.

Nintendo. (2005). Animal Crossing: Wild World [Nintendo DS]. Nintendo EAD. Kyoto, Japan.

Nintendo. (2008). Animal Crossing: City Folk [Wii]. Nintendo EAD. Kyoto, Japan.

Nintendo. (2013). Animal Crossing: New Leaf [Nintendo 3DS]. Nintendo EAD. Kyoto, Japan.

Nintendo. (2006). Chibi-Robo! [GameCube]. Skip Ltd. Shibuya, Tokyo, Japan.

Nintendo. (2014). Tomodachi Life [Nintendo 3DS]. Nintendo SPD. Kyoto, Japan.

Nutt, C. (2013, June 20). An Inviting Mini-World: How Nintendo Made Animal Crossing. Retrieved from Gamasutra website: https://www.gamasutra.com/view/feature/194661/an_inviting_miniworld_how_.php 
87 Loading... The Journal of the Canadian Game Studies Association Vol 13(22): 59-71

http://loading.gamestudies.ca

Patsavas, A. (2014). Recovering a Cripistemology of Pain: Leaky Bodies, Connective Tissue, and Feeling Discourse. Journal of Literary \& Cultural Disability Studies, 8(2), 203-218.

Personalities. (n.d.) In Animal Crossing Wiki. Retrieved October 15, 2019 from https://animalcrossing.fandom.com/wiki/Category:Personalities

Personalities. (n.d.) In Animal Crossing: New Leaf Wiki. Retrieved October 15, 2019 from https://new-leaf.fandom.com/wiki/Personalities

Pruett, J. (2019). On Feeling Productive: Videogames and Superfluous Labor. Theory \& Event, 22(2), 402-416.

Juul, J. (2012). Social Meaning and Social Goals. In A Casual Revolution: Reinventing Video Games and Their Players (pp. 121-128). The MIT Press.

Revivo, G., Amstutz, D. K., Gagnon, C. M., \& McCormick, Z. L. (2019). Interdisciplinary Pain Management Improves Pain and Function in Pediatric Patients with Chronic Pain Associated with Joint Hypermobility Syndrome. PM\&R, 11(2), 150-157. https://doi.org/10.1016/j.pmrj.2018.06.018

Samaha, A. M. (2007). What Good Is the Social Model of Disability? The University of Chicago Law Review, 74(4), 1251. https://doi.org/10.2307/20141862

"Slice of life, n.". OED Online. September 2019. Oxford University Press. https://www-oedcom.ezproxy.depaul.edu/viewdictionaryentry/Entry/181726

Styan, J. L. (1983). Realism in France Antoine and the ThéâtreLibre. In Modern Drama in Theory and Practice: Volume 1, Realism and Naturalism. Cambridge University Press.

Sullivan, M. J. L., Bishop, S. R., \& Pivik, J. (1995). The Pain Catastrophizing Scale: Development and validation. Psychological Assessment, 7(4), 524-532.

Sullivan, M. J. L. (2009). The Pain Catastrophizing Scale: User Manual. (5th ed.). n.p.: Author.

Tanaka, M. (2014). Trends of Fiction in 2000s Japanese Pop Culture. EJCJS, 14(2), 15.

Terzi, L. (2004). The Social Model of Disability: A Philosophical Critique. 19.

Treede, R., Rief, W., Barke, A., Aziz, Q., Bennett, M. I., Benoliel, R., . . Wang, S. (2015). A classification of chronic pain for ICD-11. Pain,156(6), 1003-1007.

Trost, Z., \& Parsons, T. (2014). Beyond distraction: Virtual reality graded exposure therapy as treatment for pain-related fear and disability in chronic pain. Journal of Applied Biobehavioral Research, 19(2), 106-126. doi:10.1111/jabr.12021 
88 Loading... The Journal of the Canadian Game Studies Association Vol 13(22): 59-71

http://loading.gamestudies.ca

van den Boogaart T. (2014). Bernband [Computer Software].

Williams, K. M. (2018). My Sister's Keeper: Sibling Social Support and Chronic Illness. Journal of Medical Humanities, 39(2), 135-143. https://doi.org/10.1007/s10912-0169394-4

Xseed Games. (2014-2016). Story of Seasons series. Marvelous. Tokyo, Japan. 